\title{
Role of the microbial population on the flavor of the soft-bodied cheese Torta del Casar
}

\author{
Elena Ordiales, ${ }^{*}$ Alberto Martín, $\dagger^{1}$ María José Benito, $†$ Alejandro Hernández, $†$ Santiago Ruiz-Moyano, $†$ \\ and María de Guía Córdoba† \\ *Agricultura, Centro Tecnológico Agroalimentario Extremadura, Ctra. Villafranco a Balboa Km. 1.2, Villafranco del Guadiana, 06195 Badajoz, \\ Spain \\ †Nutrición y Bromatología, Escuela de Ingenierías Agrarias, Universidad de Extremadura, Ctra. de Cáceres s/n, 06071 Badajoz, Spain
}

\begin{abstract}
The purpose of this work was to investigate the influence of the spontaneous microbial population on the flavor of Torta del Casar cheese. A total of 16 batches of cheeses with different microbial qualities were used. Their physicochemical and microbial characteristics were evaluated during ripening and then related with the volatile compounds, taste, and flavor properties of the finished cheeses. Acids were the most abundant volatile compounds, followed by alcohols and carbonyls. The amount of acetic acid and several alcohols were linked to cheeses with higher counts of lactic acid bacteria (LAB), whereas Enterobacteriaceae counts were associated with semivolatile fatty acids. The grampositive catalase-positive cocci counts were correlated with esters and methyl ketones. Although the role of the LAB in the flavor development of Torta del Casar is the most relevant, other microbial groups are necessary to impart the flavor of the cheese and to minimize the possible off-flavor derived from excessive concentrations of LAB metabolites, such as acetic acid.
\end{abstract}

Key words: lactic acid bacteria, gram-positive catalase-positive cocci, volatile compound, soft-bodied cheese

\section{INTRODUCTION}

Torta del Casar is a high-quality, Spanish soft-bodied cheese marketed under the Registry of the Protected Designation of Origin Torta del Casar (Casar de Cáceres, Cáceres, Spain) in accordance with the Regulations of the European Commission (European Commission, 2003; EC 1491/2003). This type of cheese is made from raw sheep milk with only the dried flowers of the plant Cynara cardunculus as rennet and without any deliberate addition of a starter, and is much appreciated

Received January 17, 2013.

Accepted May 15, 2013.

${ }^{1}$ Corresponding author: amartin@unex.es by consumers for its high quality and unique flavor. The use of Merino ewe raw milk and plant coagulant provides a characteristic slightly bitter taste and a spreadable texture (Delgado et al., 2010b). One of the major problems associated with raw milk cheeses is the presence of undesirable microorganisms throughout the manufacture and ripening processes. Use of raw milk, and thus the absence of any standardizing thermal process, coupled with different milking and handling protocols, and thus variation in the hygiene conditions prevailing in the farmhouses, leads to extensive and unpredictable variability (Pereira et al., 2010).

Conversely, the adventitious microflora of the raw milk and coagulant extract will also play a relevant role in forming the cheese's volatile fraction and, consequently, the sensory characteristics (Freitas and Malcata, 2000; Tavaria et al., 2004; Fernández-García et al., 2006). According to Buchin et al. (1998), the indigenous milk microflora seems to be responsible for the production of the intense flavor in raw milk cheeses, a flavor which is associated with higher amounts of FA, alcohols, and sulfur compounds. As a consequence, each product has a characteristic and unique composition of volatile components (Plutowska and Wardencki, 2007).

Microbial characterization of Torta del Casar cheese has been described previously (Poullet et al., 1991, 1993; Cáceres et al., 1997), although the role of each microbial group on the flavor of this type of cheese has not been clearly defined. Delgado et al. (2010a) studied the volatile profile and changes during ripening in this cheese to determine the compounds that provide its characteristic aroma. Those authors described the greater importance of carboxylic acids with origins in microbial activity and AA degradation as a unique characteristic associated with the typical aroma of Torta del Casar soft cheese, and which could differentiate its aroma from other cheeses on the market. The objective of the present work was to study the effect of the indigenous microbial groups from raw milk and vegetable rennet on the flavor of Torta del Casar cheese to design a specific starter culture. 


\section{MATERIALS AND METHODS}

\section{Torta del Casar Cheese-Making Procedure}

A total of 16 different batches of Torta del Casar were manufactured, producing 10 cheeses per batch, from unpasteurized Merino ewe milk to which no starter cultured was added. Each batch was clotted using samples of $C$. cardunculus L. rennet with different origins and microbial qualities. The aqueous extracts from the cardoon $C$. cardunculus $\mathrm{L}$. were prepared from $50 \mathrm{~g}$ of dried flowers in $1 \mathrm{~L}$ of water, leaving them to macerate for $24 \mathrm{~h}$, and adding $10 \mathrm{~mL}$ of this extract per liter of milk at 28 to $30^{\circ} \mathrm{C}$ for each $32 \mathrm{~L}$ of milk per batch. After pressing $\left(2 \mathrm{~kg} / \mathrm{cm}^{2}\right.$ during $\left.2 \mathrm{~h}\right)$, the cheeses were immersed in a salt solution [16\% (wt/vol) $\mathrm{NaCl}]$ for $4 \mathrm{~h}$. The ripening took place at a temperature of 5 to $10^{\circ} \mathrm{C}$ and relative humidity of 85 to $90 \%$ throughout the ripening period of $60 \mathrm{~d}$. Three cheeses of each batch were randomly taken for physicochemical and microbial analysis after 2,30 , and $60 \mathrm{~d}$ of ripening.

\section{Physicochemical Parameters}

The moisture content of the cheeses was determined by dehydration at $100^{\circ} \mathrm{C}$ to a constant weight by the recommended methods of AOAC International (2005). Water activity was determined using an FA-St/1 apparatus from GBX (France Scientific Instrument, Romans, France). The $\mathrm{pH}$ was measured using a Crison model 2002 pH meter (Crison Instruments, Barcelona, Spain).

\section{Microbial Counts}

For the microbial counts and isolates, 10-g aliquots of each cheese sample were taken aseptically, transferred to sterile plastic pouches, 10-fold diluted with $1 \%$ peptone water (Pronadisa, Alcobendas, Madrid, Spain), and homogenized for $120 \mathrm{~s}$ using the laboratory Stomacher Lab-Blender 400 (Seward Lab, London, England). Serial 10-fold dilutions were prepared from the same solution and inoculated onto agar plates. The same procedure was performed for microbial counts of raw ewe's milk and rennet extracts from 10-mL aliquots of milk and each rennet sample, respectively.

Lactobacillus were grown in MRS agar (Oxoid, Basingstoke, UK), of which the $\mathrm{pH}$ was adjusted to 5.6 with acetic acid (10\%), incubated at $37^{\circ} \mathrm{C}$ for $48 \mathrm{~h}$ in a $10 \% \mathrm{CO}_{2}$ air atmosphere. The M17 agar (Scharlab, Barcelona, Spain) was used for Lactococcus and Slanezt and Bartley (Scharlab) for Enterococcus. These media were incubated for $48 \mathrm{~h}$ at $37^{\circ} \mathrm{C}$. The gram-positive catalase-positive cocci (GPCP) and Enterobactericeae counts were determined in MSA agar (Oxoid) at $30^{\circ} \mathrm{C}$ for $48 \mathrm{~h}$, and violet red bile glucose agar (Merck, Germany) at $37^{\circ} \mathrm{C}$ for $48 \mathrm{~h}$, respectively. In both culture media, typical colonies were counted. The yeast counts were determined in potato dextrose agar (Merck) at $25^{\circ} \mathrm{C}$ for $48 \mathrm{~h}$.

\section{Volatile Compound Analysis}

Volatile compounds were determined from the samples of cheeses ( 3 cheeses of each batch) at the end of ripening, having previously been vacuum-packed and stored at $-80^{\circ} \mathrm{C}$ until analysis. Frozen samples were minced and $1 \mathrm{~g}$ was weighed into a $10-\mathrm{mL}$ headspace vial (Hewlett-Packard, Palo Alto, CA) and sealed with a PTFE butyl septum (Perkin-Elmer, Foster City, CA) in an aluminum cap. Volatile compounds were extracted by solid-phase microextraction (SPME; Ruiz et al., 1998) with a 10-mm long, 100-mm thick fiber coated with poly-dimethylsiloxane (Supelco Co., Bellefonte, PA). Prior to collection of volatiles, the fiber was preconditioned at $220^{\circ} \mathrm{C}$ for $50 \mathrm{~min}$ in the GC injection port. The SPME fiber was inserted into the headspace vial through the septum and exposed to the headspace for $30 \mathrm{~min}$ at $40^{\circ} \mathrm{C}$ in a water bath. The same fiber was used for the random analyses of the samples in continuous sessions.

Gas chromatography-mass spectrometry analyses were performed as described by Ruiz et al. (1998), using an Agilent $6890 \mathrm{GC} / 5973$ MS system (Agilent Technologies, Santa Clara, CA). A 5\% phenyl, 95\% polydimethylsiloxane column $(30 \mathrm{~m} \times 0.32 \mathrm{~mm}$ i.d., $1.05 \mu \mathrm{m}$ film thickness; Agilent) was used for the separation of volatile compounds. To calculate the Kováts index of the compounds, N-alkanes (R-8769, Sigma Chemical Co., St. Louis, MO) were run under the same conditions (Kováts, 1965). The NIST/EPA/NIH mass spectrum library NIST 05 (comparison quality > 90\%; http://www.nist.gov/srd/nist1a.cfm; National Institute of Standards and Technology, Gaithersburg, MD) and Kováts indices were used to identify the volatile compounds (Kondjoyan and Berdagué, 1996). Additionally, the identity of certain analytes was confirmed by a comparison of the retention time and mass spectra using a laboratory-built MS spectral database, obtained from chromatographic runs of pure compounds performed with the same equipment and conditions. Ion counts of peak areas were used to obtain and compare gross differences in compound abundances.

\section{Sensory Evaluation}

Fifteen panelists, previously selected and trained under International Organization for Standardization standards (ISO, 2006; UNE-ISO 4121:2006) with sam- 
ples of Torta del Casar, were asked to characterize the sensory quality of the cheese batches. The cheeses were cut into slices approximately $5 \mathrm{~mm}$ thick. The slices were equilibrated for $30 \mathrm{~min}$ at room temperature before serving. Descriptive analyses were made according to international standard methods. Nine parameters related to taste (salty, acidic, and bitter), pungency sensation, and flavor (intensity, persistence, rancidity, ewe's milk character, and off-flavor) were assessed using a structured line scale with intensity descriptors at the end points $(1=$ low; $10=$ high $)$. Samples were 3 -digit coded and the order of serving was determined by random permutation. Two panel replicates were carried out on each sample. The response to each indicator was taken as the mean of the panelists' responses.

\section{Statistical Analysis}

Statistical analyses of the data were carried out using SPSS for Windows 15.0. (SPSS Inc., Chicago, IL). Descriptive statistics were determined, and the mean values of the evolution of the physicochemical and microbial parameters of the cheese samples were studied by one-way ANOVA and separated by Tukey's honestly significant differences test $(P \leq 0.05)$. A principal component analysis was performed on the mean values of volatile compounds in the cheeses at the end of ripening and on the mean values of microbial counts during ripening to study the effect of the microbial groups on the volatile profile of the cheeses. The influence of microbial groups and volatile compounds on sensorial parameters was evaluated by Pearson correlation coefficients. Pearson correlation coefficients were determined and a linear regression analysis made between the microbial counts and the most relevant volatile compounds.

\section{RESULTS AND DISCUSSION}

\section{Microbial Population in Raw Ewe Milk and Aqueous Extracts of C. cardunculus}

Counts of the microorganisms in raw ewe's milk and aqueous extracts are presented in Figure 1. Lactococci counts were at higher levels than those of the remaining microbial groups in the raw ewe milk, and the yeast population was predominant in the aqueous extracts. Except for the yeasts, all the microbial groups studied in the raw ewe milk had counts greater than $3 \mathrm{log}$ $\mathrm{cfu} / \mathrm{g}$, with lactococci, lactobacilli, and GPCP cocci exceeding $4 \log \mathrm{cfu} / \mathrm{g}$. Similar or higher counts of these microbial groups are usually found in raw ewe and goat milk for cheese making (Mas-Mayoral et al., 1991; Elortondo et al., 1998; Alonso-Calleja et al., 2002; Caridi, 2003). With respect to the microbial counts reached in the coagulant extracts, they showed a high variability among the different batches used, with mean values for yeasts and Enterobacteriaceae being higher than for raw milk. These results suggest that, in addition to the milk, the vegetable coagulant could relevantly influence the microbial quality of Torta del Casar.

\section{Evolution of the Physicochemical and Microbial Parameters During Cheese Ripening}

The evolution of the physicochemical parameters during ripening is presented in Figure 2. Significant differences $(P<0.05)$ were observed in moisture and $\mathrm{pH}$ values during cheese ripening, with decreases until the end of processing. The mean moisture values varied from 56.61 ( $2 \mathrm{~d}$ of ripening) to $40.81 \%$ (60 d of ripening), and the $\mathrm{pH}$ values ranged from 6.85 ( $2 \mathrm{~d}$ of ripening) to 5.65 (60 d of ripening). The results were similar to those obtained for other soft-bodied cheeses (Roa et al., 1999; Sanjuán et al., 2002). The pH changes may reflect the major metabolic activity of lactic acid bacteria in this type of ewe milk cheese. Indeed, the mean counts of Lactobacillus and Lactococcus were greater than $8 \mathrm{log} \mathrm{cfu} / \mathrm{g}$ throughout ripening, with high variability among batches in the initial stage $(2 \mathrm{~d}$ of ripening). In the case of the Enterococcus, GPCP cocci, and Enterobacteriaceae, the counts during ripening were essentially constant with values close to $7 \log \mathrm{cfu} / \mathrm{g}$, and the yeast counts were around $4 \mathrm{log} \mathrm{cfu} / \mathrm{g}$ during the ripening of the cheeses (Figure 1). These counts were in concordance with those found in other fresh soft cheeses clotted with vegetable rennets after $60 \mathrm{~d}$ of ripening. In particular, lactic acid bacteria appear to be the predominant microbial groups in Serra da Estrela cheese (Tavaria and Malcata 1998), eventually reaching viable numbers of around $7 \mathrm{log} \mathrm{cfu} / \mathrm{g}$ by the time of consumption (Pintado et al., 2010). Likewise, Dahl et al. (2000) observed counts of GPCP cocci and Enterobacteriaceae of around $6 \mathrm{log} \mathrm{cfu} / \mathrm{g}$ in this type of cheese. The presence of high numbers of enterobacteria and coliforms is indicative of poor hygienic conditions; however, it is typical of cheeses made from raw milk, and has been reported by other workers (Coton et al. (2012). Enterobacteriaceae have frequently been found during cheese manufacture (Morales et al., 2003; Mounier et al., 2005; Chaves-Lopez et al., 2006). Obviously, these high levels of microorganisms during ripening may be playing a relevant role in the development of the sensory characteristics of Torta del Casar cheese, including its flavor.

\section{Volatile Compounds}

Over 55 volatile compounds were identified in the samples, including hydrocarbons, alcohols, aldehydes, 
Raw milk Coagulant extract

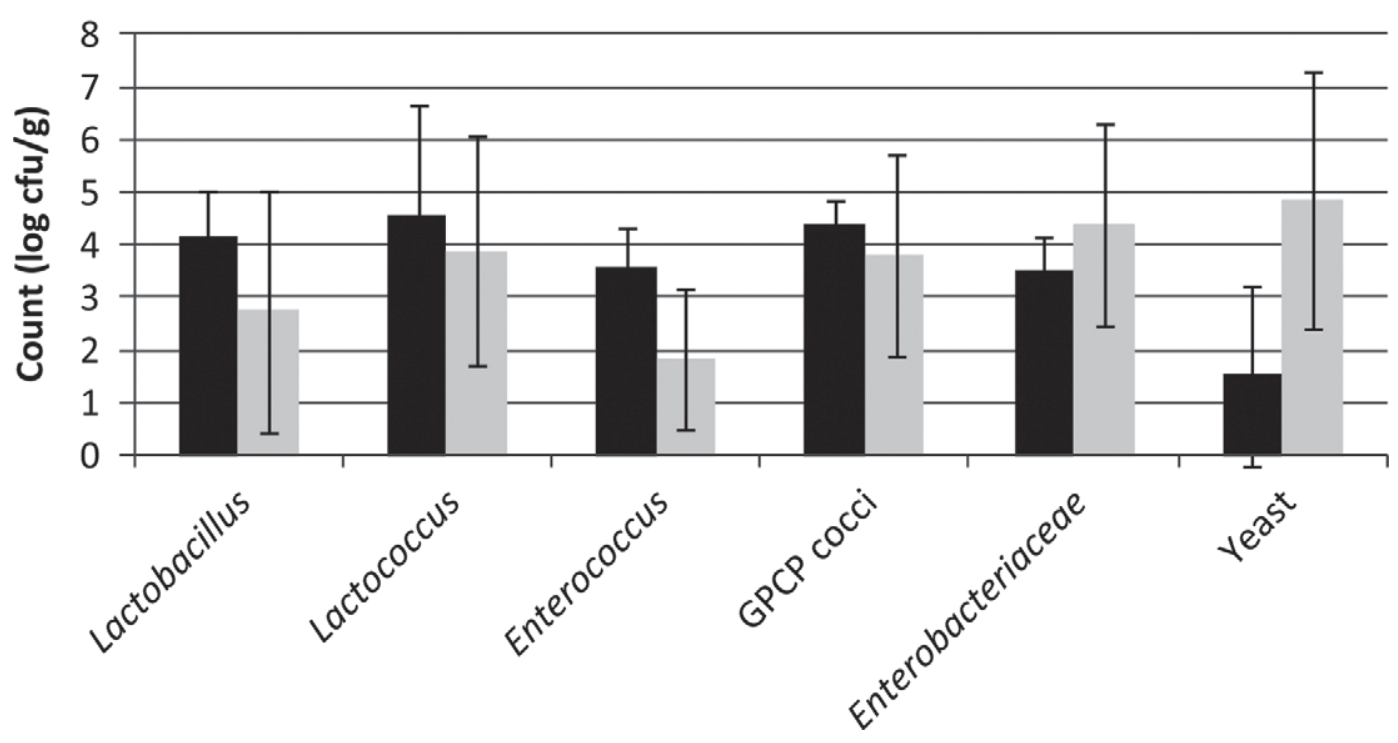

Figure 1. Microbial counts in raw ewe milk and coagulant extract. GPCP cocci = gram-positive, catalase-positive cocci.

ketones, carboxylic acids, and esters. In general, great differences were observed in the volatile profiles among the cheese batches, with several of the aforementioned volatile compounds being detected only at low frequencies or at very low levels. Most of the identified compounds have also been reported in different kinds of cheeses, including other soft-bodied cheeses similar to Torta del Casar (Dahl et al., 2000; Ferreira et al., 2009; Delgado et al., 2010a).

Hydrocarbons formed approximately $10 \%$ of the total mean area of volatile compounds. Aliphatic and branched hydrocarbons are considered to be noncontributors to food flavor, and are not among the most odor-active compounds described for cheeses (Arora et al., 1995). Aromatic hydrocarbons, responsible for smoky, phenolic-like odors in foods, represented less than $0.1 \%$ of the total area of the volatile compounds.

Table 1 presents the data for the carbonyls (aldehydes and ketones were 0.61 and $9.96 \%$, respectively, of the total mean area). Most of these compounds were linear carbonyls which have been attributed mainly to the oxidative, but also to the enzymatic, decomposition of lipids (Engels et al., 1997). The appearance of methyl ketones in cheese is due mainly to the lipolytic action of microorganisms, such as fungi. Diacetyl (butane-2,3dione) produced as a consequence of microbial lactose and citrate metabolism was found at high levels in some batch samples, but was not detected in others. This volatile compound is appreciated for its buttery and nut-like notes, and is identified as a key aroma component of other kinds of cheese, such as Camembert,
Cheddar, and Emmental (Curioni and Bosset, 2002). Diacetyl can be reduced to acetoin, which presented the highest levels of the ketones in our study. This compound has been described previously in Torta del Casar, although as a minor component (Delgado et al., 2010a). Both diacetyl and acetoin are known to be important for the characteristic aromas of several cheeses, an example being Cheddar (Izco and Torre, 2000).

Alcohols were the second most abundant compounds isolated in the headspace of Torta del Casar in this study, mainly due to the high mean values of ethanol, 3-methyl 1-butanol, 1-butanol, and 2,3 butanediol. Ethanol can be considered to be a direct product of lactose fermentation, whereas 3-methyl-1-butanol is originated by the reduction of the Strecker aldehyde produced from leucine and confers a pleasant fresh cheese aroma (Moio et al., 1993). The origin of 2,3 butanediol could be the reduction of acetoin.

Acids were the most abundant volatile compounds described by Delgado et al. (2010a) for this kind of cheese. Of the acids found in the present work, the 2 most abundant were acetic and butanoic. Acetic acid and propionic acid have a typical vinegar odor. The former is a major odorant of several cheese varieties, including Cheddar, Roncal, and Emmental (Preininger, et al., 1996). Butanoic acid has a rancid, cheese-like odor and plays an important role in the flavor of many cheese types, such as Camembert, Cheddar, Grana, and Roncal (Curioni and Bosset, 2002).

Fatty acids with 6 or more carbons have been attributed mainly to microbial or oxidative decomposition 

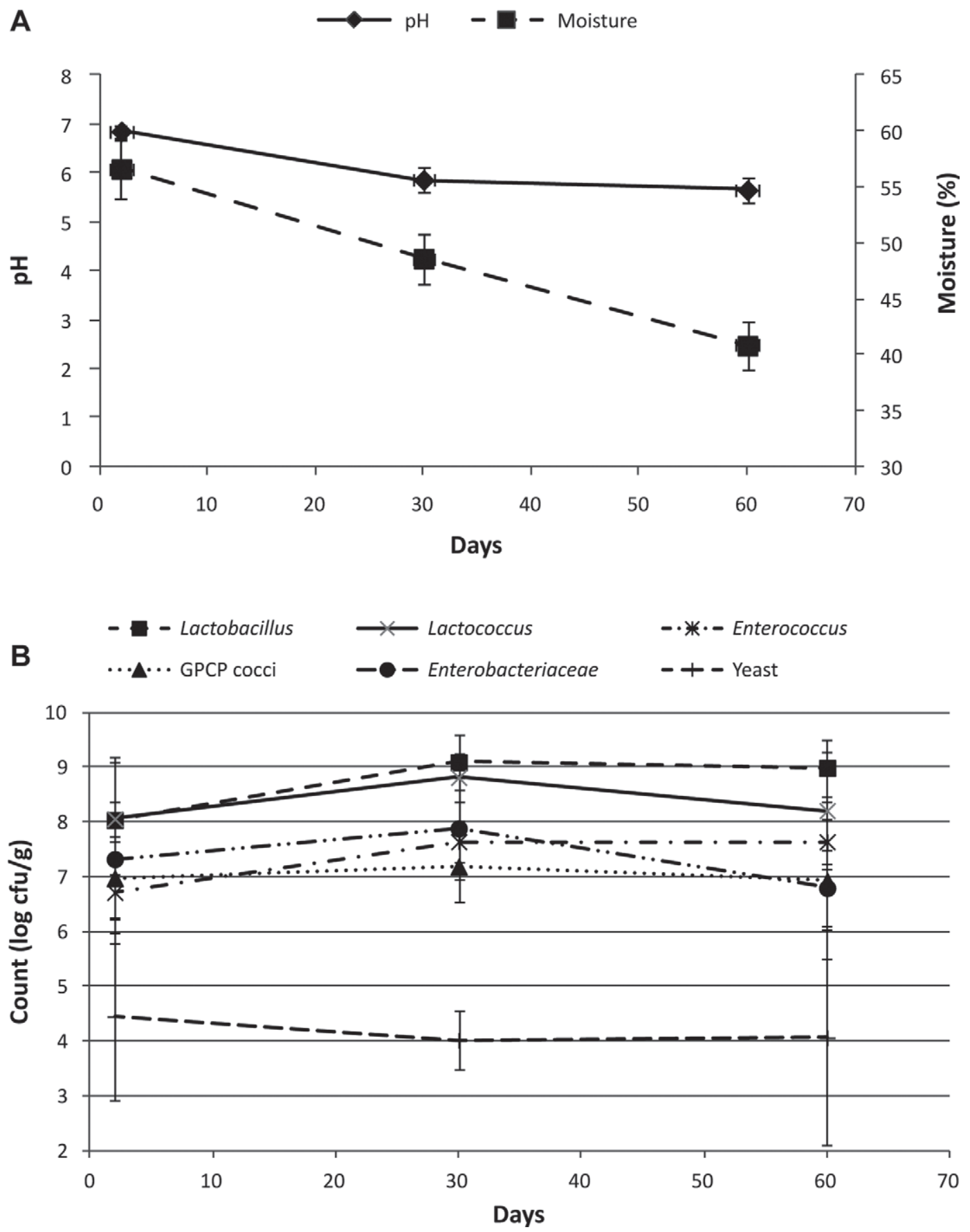

Figure 2. Evolution of moisture and $\mathrm{pH}$ values (A) and microbial counts (B) during ripening of Torta del Casar cheese. GPCP cocci = gram-positive, catalase-positive cocci.

of lipids in the case of linear carboxylic acids. Hexanoic acid represented $2.87 \%$ of the total mean area of volatile acids and is reported as seeming to contribute significantly to the aroma of several kinds of cheese (Curioni and Bosset, 2002). The branched carboxylic acids found (i.e., 2-methyl propionic and 3-methyl butanoic acids) could originate from the oxidation of their respective Strecker aldehydes, 2-methyl propanal and 3 -methy butanal. These precursors can also be formed in cheese through deamination and decarboxylation by bacteria (Engels et al., 1997).

A total of 9 esters were found, although they did not reach high values. The microbial population present in Torta del Casar was able to form these compounds by 
Table 1. Volatile compounds from end-ripening Torta del Casar cheeses

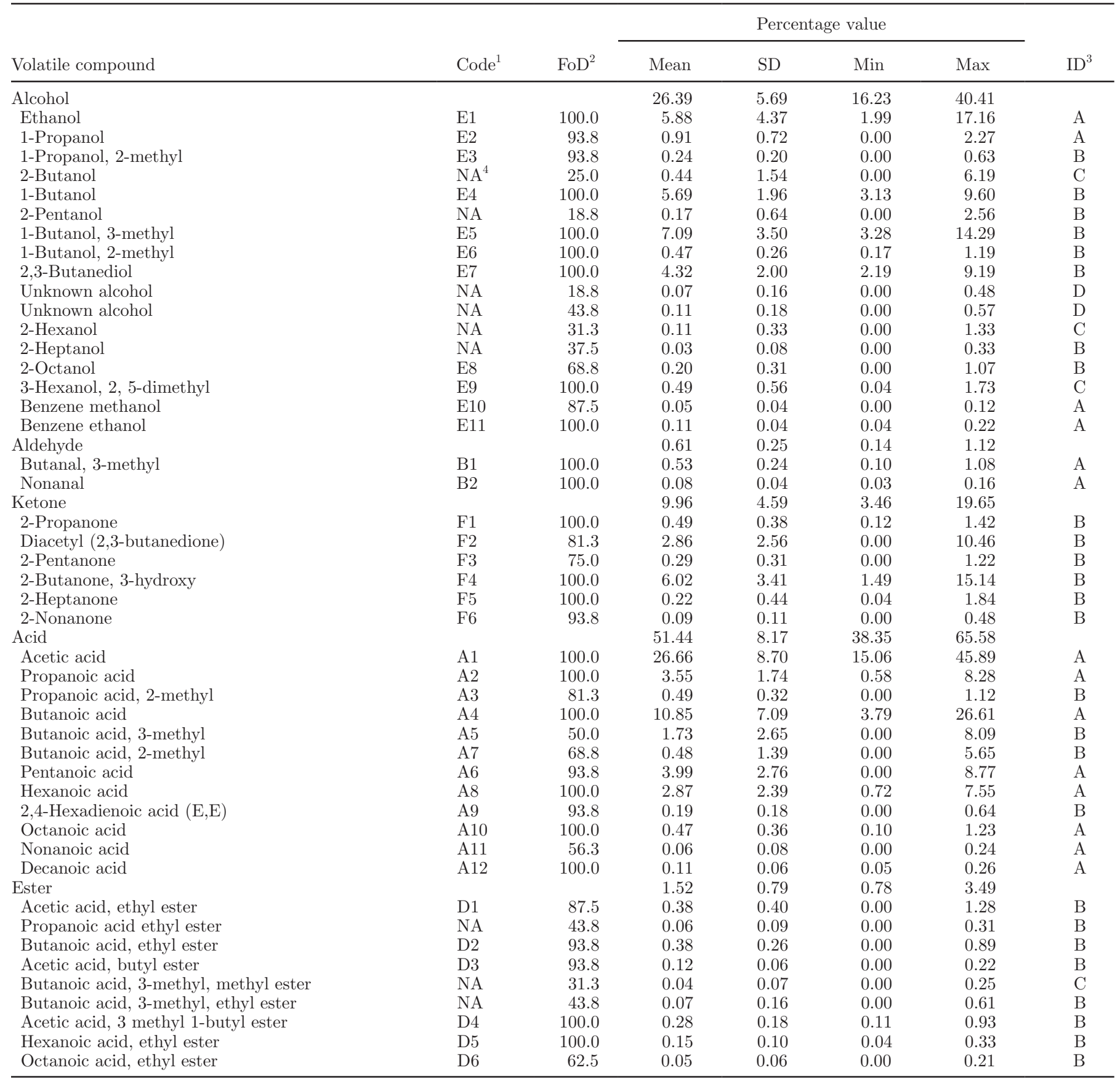

${ }^{1}$ Code for principal component analysis.

${ }^{2} \mathrm{FoD}=$ frequency of detection in samples analyzed.

${ }^{3} \mathrm{ID}$ = reliability of identification: (A) identified by comparison with standard compounds; (B) tentatively identified by the NIST/EPA/ $\mathrm{NIH}$ mass spectrum library (comparison quality >90\%; http://www.nist.gov/srd/nist1a.cfm; National Institute of Standards and Technology, Gaithersburg, MD) and Kováts index; (C) tentatively identified by the NIST/EPA/NIH mass spectrum library (comparison quality $>90 \%$ ); (D) tentatively identified by the NIST/EPA/NIH mass spectrum library (comparison quality <90\%).

${ }^{4} \mathrm{NA}=$ volatile compounds detected at low frequency or trace amount not included in principal component analysis.

esterification reactions between short- to medium-chain FA and the alcohols derived from lactose fermentation or from AA catabolism. Most of those detected were ethyl esters, with ethyl acetate being the main compound (Table 1). They are known for their important role in the formation of a fruity character in cheese, 
Table 2. Sensory attributes at the end of cheese ripening and their correlations with microbial population

\begin{tabular}{|c|c|c|c|c|c|c|c|c|}
\hline \multirow[b]{2}{*}{ Sensory attribute } & \multicolumn{2}{|c|}{$\begin{array}{l}\text { Descriptive } \\
\text { statistics }^{1}\end{array}$} & \multicolumn{6}{|c|}{ Microbial population correlation } \\
\hline & Mean & $\mathrm{SD}$ & Lactobacillus & Lactococcus & Enterococcus & $\begin{array}{c}\mathrm{GPCP}^{2} \\
\text { cocci }\end{array}$ & Enterobacteriaceae & Yeast \\
\hline \multicolumn{9}{|l|}{ Taste attribute } \\
\hline Salty & 4.68 & 0.47 & $0.568^{*}$ & $0.694^{* *}$ & $0.564^{*}$ & & & \\
\hline Bitter & 3.21 & 0.47 & & $0.610^{*}$ & & & & \\
\hline \multicolumn{9}{|l|}{ Flavor attribute } \\
\hline Intensity & 6.11 & 0.46 & & $0.676^{* *}$ & & & & \\
\hline Persistence & 5.83 & 0.40 & & & & & & \\
\hline Ewe's milk & 5.32 & 0.53 & & & & $0.565^{*}$ & & \\
\hline Rancid & 0.62 & 0.17 & & & & & & \\
\hline After-flavor & 3.38 & 0.67 & & & & & & \\
\hline Off flavor & 0.99 & 0.32 & & & & & & \\
\hline
\end{tabular}

${ }^{1}$ Scale anchors: $0=$ low and $10=$ high. Reported values are mean values of 2 replicates.

${ }^{2}$ Gram-positive catalase-positive cocci.

$* P<0.05 ; * * P<0.01$.

as they have low detection thresholds (Curioni and Bosset, 2002). Delgado et al. (2010a) found that ester levels were low at the beginning and then increased at the end of ripening in Torta del Casar, being the second most abundant group of compounds isolated(after 90 $\mathrm{d}$ of ripening). In our study, the end of processing was considered to be $60 \mathrm{~d}$ of ripening, which could partially explain the lower amount of esters and other volatile compounds, such as methyl ketones, found. Ethyl butanoate and ethyl hexanoate have been identified as potent odorants of Cheddar and Gorgonzola cheeses (Curioni and Bosset, 2002).

\section{Effect of the Microbial Population on the Volatile Profile of Torta del Casar Cheese}

The principal component analysis of the mean microbial counts and volatile compounds showed the influence of microbial population on the volatile profile of the cheese samples studied (Figure 3). The first axis accounted for $25.22 \%$ of the variance and was mainly defined by Enterobacteriaceae counts associated with volatile compounds such as butanoic acid (A4), hexanoic acid (A8), octanoic acid (A10), and 3-methyl butanol (E5). Semivolatile FA have been correlated with Enterobacteriaceae counts in Serra da Estrela cheese, which is elaborated from raw ewe's milk (Dahl et al., 2000). In the present study, these compounds showed a negative correlation with the amounts of acetic acid (A1), acetic acid butyl ester (D3), and such alcohols as 2-octanol (E8), 4-octanol (E9), and benzenemethanol (E10), which were linked to cheeses with higher counts of lactobacilli, enterococci, streptococci, and, to a lesser extent, yeasts. The origin of acetic acid in cheeses has been linked to glycolysis and citrate metabolism by lactic acid bacteria (Urbach, 1995). The GPCP cocci counts were defined by principal component 1 and 2, with this microbial group being correlated with the main esters found (acetic acid ethyl ester, butanoic acid ethyl ester) and methyl ketones such as 2-heptanone and 2-nonanone. Indeed, GPCP cocci have been described as being among the microorganisms involved in ester formation, and methyl ketones such as heptan-2-1 and nonan-2-1 have been associated with the manufacturing process of a soft, raw goat's milk cheese, which in turn influenced the microbial activity (Sable et al., 1997). This relation between methyl ketones and GPCP cocci has also been described in Castellano cheese (Fernández García et al., 2004).

\section{Influence of the Microbial Population on the Cheese's Taste and Flavor}

To characterize the role of microbial groups on the taste and flavor of the cheeses, a correlation analysis was performed between the microbial counts and the sensorial parameters studied (Table 2). Cheeses with high counts of lactic acid bacteria, mainly Lactobacillus, obtained higher scores for the salty, acidic, and bitter taste attributes, and as a consequence for the flavor intensity attribute. This may be related to the intense fermentation and proteolytic activities during ripening driven by the high counts of these lactic acid bacteria groups, yielding such compounds as lactic acid, acetic acid, small peptides, and amines, which all have a major effect on the cheese's taste. In addition, the ewe's milk flavor descriptor was correlated with GPCP cocci counts, whereas the remaining flavor descriptors studied were not clearly associated with 
Table 3. Volatile compounds correlated with off-flavor attribute

\begin{tabular}{lc}
\hline Volatile compound & $\begin{array}{c}\text { Correlation } \\
\text { coefficient }\end{array}$ \\
\hline Acetic acid & $0.630^{* *}$ \\
Butanoic acid, 3-methyl & $0.507^{*}$ \\
Acetic acid, butyl ester & $0.524^{*}$ \\
2,3 Butanediol & $0.608^{*}$ \\
\hline
\end{tabular}

${ }^{*} P<0.05 ;{ }^{* *} P<0.01$.

any individual microbial group, including the off-flavor descriptor. This last attribute was clearly associated with some volatile compounds in the cheeses, with acetic acid and 2,3-butanediol being the most relevant (Table 3). Large amounts of these volatile compounds are undesirable. The occurrence of high levels of 2,3-butanediol in cheese has been related to a high activity of spoilage bacteria, and acetic acid has been associated with high lactic acid bacteria counts in cheeses (Dahl et al., 2000), suggesting that uncontrolled growth of heterofermentative LAB could have a negative effect on the flavor of Torta del Casar. Among the volatile compounds that showed significant correlation with the off-flavor attribute, acetic acid presented the clearest regression with the microbial counts. The influence of other microbial groups on the acetic acid present in the cheeses was studied by a partial least-squares regression method. The model $(\mathrm{r}=0.787)$ indicated that $62.0 \%$ of the variation in the acetic acid concentration could be predicted from the counts of Lactobacillus and GPCP cocci [1.8E8 lactobacilli (log cfu/g) - 1.78E8GPCP cocci $(\log \mathrm{cfu} / \mathrm{g})-0.99 \mathrm{E} 8]$. The negative regression coefficient obtained for the latter microbial group reflects this group's action in modulating the production of acetic acid in the cheese.

\section{CONCLUSIONS}

The indigenous microbial population plays a major role in the development of the flavor of the soft cheese, Torta del Casar. Although the role of lactic acid bacteria is the most relevant, other microbial groups are necessary to impart the characteristic flavor of this cheese, and to minimize the possible off-flavor deriv-

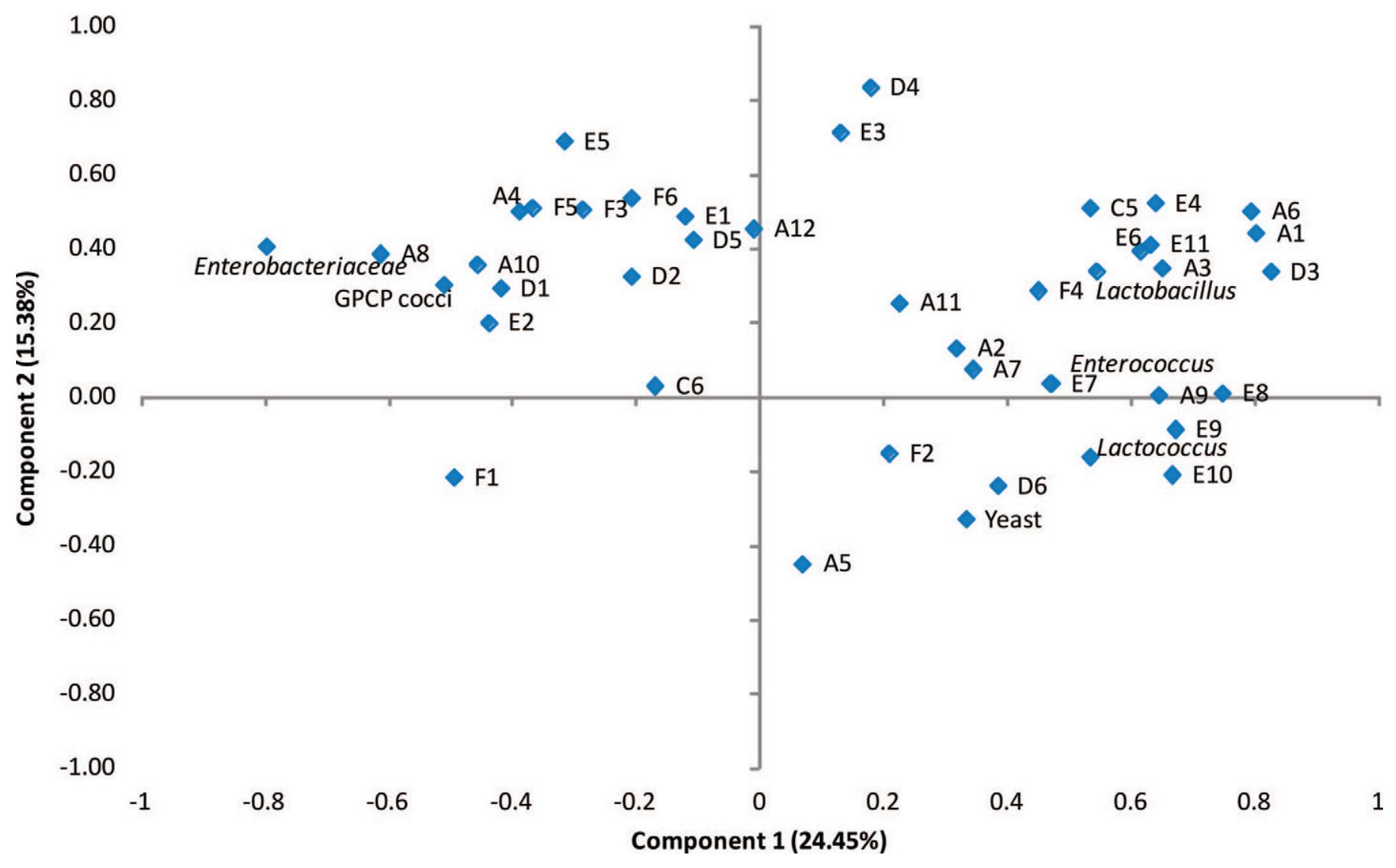

Figure 3. Principal component analysis of microbial counts and the main volatile compounds found at the end of cheese ripening (60 d). GPCP cocci = gram-positive, catalase-positive cocci. See Table 1 for definition of codes. Color version available in the online PDF. 
ing from excessive concentrations of lactic acid bacteria metabolites. Therefore, a selection of suitable strains to improve the flavor of Torta del Casar cheese would include not only lactic acid bacteria but also strains from other microbial groups, such as GPCP.

\section{ACKNOWLEDGMENTS}

The authors are grateful to M. Cabrero and J. Hernández Barreto (Nutrición y Bromatología, Escuela de Ingenierías Agrarias, Universidad de Extremadura, Badajoz, Spain) for technical assistance and PDO "Torta del Casar" (Casar de Cáceres, Spain) for technical support.

\section{REFERENCES}

Alonso-Calleja, C., J. Carballo, R. Capita, A. Bernardo, and M. L. García-López. 2002. Changes in the microflora of Valdeteja raw goat's milk cheese throughout manufacturing and ripening. Lebenson. Wiss. Technol. 35:222-232.

AOAC International. 2005. Official Methods of Analysis. 19th ed. AOAC International, Washington, DC.

Arora, G., F. Cormier, and B. Lee. 1995. Analysis of odor-active volatiles in Cheddar cheese headspace by multidimensional GC/MS/ sniffing. J. Agric. Food Chem. 43:748-752.

Buchin, S., V. Delague, G. Duboz, J. L. Berdagué, E. Beuvier, S. Pochet, and R. Grappin. 1998. Influence of pasteurization and fat composition of milk on the volatile compounds and flavor characteristics of a semihard cheese. J. Dairy Sci. 81:3097-3108.

Cáceres, P., D. Castillo, and M. Pizarro. 1997. Secondary flora of Casar de Cáceres cheese: Characterization of Micrococcaceae. Int. Dairy J. 7:531-536.

Caridi, A. 2003. Identification and first characterization of lactic acid bacteria isolated from the artisanal ovine cheese Pecorino del Poro. Int. J. Dairy Technol. 56:105-110.

Chaves-Lopez, C., M. De Angelis, M. Martuscelli, A. Serio, A. Paparella, and G. Suzzi. 2006. Characterization of the Enterobacteriaceae isolated from an artisanal Italian ewe's cheese (Pecorino Abruzzese). J. Appl. Microbiol. 101:353-360.

Coton, M., C. Delbés-Paus, F. Irlinger, N. Desmasures, A. Le Fleche, V. Stahl, M. C. Montel, and E. Coton. 2012. Biodiversity and assessment of potential risk factors of gram-negative isolates associated with French cheeses. Food Microbiol. 29:88-98.

Curioni, P. M., and J. O. Bosset. 2002. Key odorants in various cheese type as determined by gas chromatography-olfactometry. Int. Dairy J. 12:959-984.

Dahl, S., F. K. Tavaria, and F. X. Malcata. 2000. Relationships between flavour and microbiological profiles in Serra da Estrela cheese throughout ripening. Int. Dairy J. 10:255-262.

Delgado, F. J., J. González-Crespo, R. Cava, J. García-Parra, and R. Ramírez. 2010a. Characterisation by SPME-GC-MS of the volatile profile of a Spanish soft cheese P.D.O. Torta del Casar during ripening. Food Chem. 118:182-189.

Delgado, F. J., J. Rodríguez-Pinilla, J. González-Crespo, R. Ramirez, and I. Roa. 2010b. Proteolysis and texture changes of a Spanish soft cheese ('Torta del Casar') manufactured with raw ewe milk and vegetable rennet during ripening. Int. J. Food Sci. Technol. 45:512-519.

Elortondo, F. J. P., P. A. Echobarria, M. Albisu, and Y. Barcina. 1998. Indigenous lactic acid bacteria in Idiazabal ewes' milk cheese. Int. Dairy J. 8:725-732.

Engels, W. J. M., R. Dekker, C. de Jong, R. Neeter, and S. Visser. 1997. A comparative study of volatile compounds in the watersoluble fraction of various types of ripened cheese. Int. Dairy J. $7: 255-263$
European Commission. 2003. Regulation (EC) 1491/2003 of European Commission of 25 of August: Registration of the Protected Designation of Origin "Torta del Casar" in the Register of Protected Designations of Origin and the Protected Geographic Indications.

Fernández-García, E., M. Carbonell, J. Calzada, and M. Núñez. 2006. Seasonal variation of the free fatty acids contents of Spanish ovine milk cheese protected by a designation of origin: A comparative study. Int. Dairy J. 16:252-261.

Fernández-García, E., P. Gaya, M. Medina, and M. Núñez. 2004. Evolution of the volatile components of raw ewes' milk Castellano cheese: Seasonal variation. Int. Dairy J. 14:39-46.

Ferreira, I. M. P. L. O., O. Pinho, and P. Sampaio. 2009. Volatile fraction of DOP "Castelo Branco" cheese: Influence of breed. Food Chem. 112:1053-1059.

Freitas, C. A., and F. X. Malcata. 2000. Microbiology and biochemistry of cheeses with Appélation d'Origine Protegée and manufactured in the Iberian Peninsula from ovine and caprine milks. J. Dairy Sci. 83:584-602.

ISO (International Organization for Standardization). 2006. UNE-ISO 4121:2006. Sensory analysis - Guidelines for the use of quantitative response scales. ISO, Geneva, Switzerland.

Izco, J. M., and P. Torre. 2000. Characterisation of volatile flavour compounds in Roncal cheese extracted by the purge and trap method and analysed by GC-MS. Food Chem. 70:409-417.

Kondjoyan, N., and J. L. Berdagué. 1996. A Compilation of Relative Retention Indices for the Analysis of Aromatic Compounds. Laboratoire Flaveur, Clemont Rerrand, France.

Kováts, E. 1965. Gas chromatographic characterization of organic substances in the retention index system. Pages 229-247 in Advances in Chromatography. J. C. Giddings, and R. A. Keller, ed. Marcel Dekker, New York, NY.

Mas Mayoral, M., J. González Crespo, and M. J. Nieto Villaseca. 1991. Casar cheese: Production, physicochemical and microbiological characteristics. Arch. Zootec. 40:359-369.

Moio, L., D. Langlois, P. Etiévant, and F. Addeo. 1993. Powerful odorants in bovine, ovine, caprine and water buffalo milk determined by means of gas chromatography-olfactometry. J. Dairy Res. 60:215-222.

Morales, P., E. Fernández-García, and M. Núñez. 2003. Caseinolysis in cheese by Enterobacteriaceae strains of dairy origin. Lett. Appl. Microbiol. 37:410-414.

Mounier, J., R. Gelsomino, S. Georges, M. Vancanneyt, K. Vandemeulebroecke, B. Hoste, S. Scherer, J. Swings, G. F. Fitzgerald, and T. M. Cogan. 2005. Surface microflora of four smear-ripened cheeses. Appl. Environ. Microbiol. 71:6489-6500.

Pereira, C. I., D. M. Neto, J. C. Capucho, M. S. Giâo, A. M. P. Gomes, and F. X. Malcata. 2010. How three adventitious lactic acid bacteria affect proteolysis and organic acid production in model Portuguese cheese manufactured from several milk sources and two alternative coagulants. J. Dairy Sci. 93:1335-1344.

Pintado, A. I., T. G. Tavares, F. K. Tavaira, and F. X. Malcata. 2010. Tradition versus modernism in cheesemaking technology: A Portuguese case study encompassing plant coagulant, non-bovine milks and adventitious microflora. Aust. J. Dairy Technol. 65:128-134.

Plutowska, B., and W. Wardencki. 2007. Aromagrams-Aromatic profiles in the appreciation of food quality. Food Chem. 101:845-872.

Poullet, B., M. Huertas, A. Sánchez, P. Cáceres, and G. Larriba. 1991. Microbial study of Casar de Cáceres cheese throughout ripening. J. Dairy Res. 58:231-238.

Poullet, B., M. Huertas, A. Sánchez, P. Cáceres, and G. Larriba. 1993. Main lactic acid bacteria isolated during ripening of Casar de Cáceres cheese. J. Dairy Res. 60:123-127.

Preininger, M., R. Warmke, and W. Grosch. 1996. Identification of the character impact flavour compounds of Swiss cheese by sensory studies of models. Z. Lebensm. Unters. For. 202:30-34.

Roa, I., M. B. López, and F. J. Mendiola. 1999. Residual clotting activity and ripening properties of vegetable rennet from Cynara cardunculus in La Serena cheese. Food Res. Int. 32:413-419.

Ruiz, J., R. Cava, J. Ventanas, and M. T. Jensen. 1998. Headspace solid phase microextraction for the analysis of volatiles in a meat 
product: Dry cured Iberian ham. J. Agric. Food Chem. 46:46884694.

Sable, S., F. Letellier, and G. Cottenceau. 1997. An analysis of the volatile flavour compounds in a soft raw goat milk cheese. Biotechnol. Lett. 19:143-145.

Sanjuán, E., R. Millán, P. Saavedra, M. A. Carmona, R. Gómez, and J. Fernández-Salguero. 2002. Influence of animal and vegetable rennet on the physicochemical characteristics of Los Pedroches cheese during ripening. Food Chem. 78:281-289.
Tavaria, F. K., and F. X. Malcata. 1998. Microbiological characterization of Serra da Estrela cheese throughout its AOP region. J. Food Prot. 61:601-607.

Tavaria, F. K., A. C. Ferreira, and F. X. Malcata. 2004. Volatile free fatty acids as ripening indicators for Serra da Estrela Cheese. J. Dairy Sci. 87:4064-4072.

Urbach, G. 1995. Contribution of lactic acid bacteria to flavour compound formation in dairy products. Int. Dairy J. 5:877-903. 